\title{
Beyond Environmental Regulatory Fragmentation: Signs of Integration in the Case of the Great Lakes Basin
}

\author{
BARRY G. RABE* and JANET B. ZIMMERMAN*
}

\begin{abstract}
Environmental regulatory fragmentation along the medium boundaries of air, land, and water in Canada and the United States serves to shift pollutants from medium to medium rather than contain or eliminate them. This pattern is particularly evident in the Great Lakes Basin where many of the most pressing environmental problems stem from pollutant transfer across medium or jurisdictional lines. The impediments to more integrated environmental regulation remain considerable in the Basin, and include the enduring single-medium orientation of federal programs and limitations of state, provincial, or regional innovation. Nonetheless, there is growing indication that regulatory integration need not be dismissed as a theoretical nicety but political impossibility. A series of recent developments indicate a shift toward greater integration in the Basin, prompted in large part by environmental policy professionals who increasingly recognize the limitations of current approaches and are willing to devise alternatives. These developments are occurring at the regional as well as state and provincial levels, and they give far greater definition than ever before to the idea of integrated environmental regulation.
\end{abstract}

Americans and Canadians have become increasingly skeptical of the capacity of their governments to devise effective domestic policy. Polling data show steady erosion in recent years in confidence levels assessing the performance of various governmental institutions in both nations, confirming general trends from recent decades (Lipset and Schneider 1983; Johnston 1986; Page and Shapiro 1992). Moreover, much of the scholarly literature analyzing the performance of these institutions takes a similarly negative tone, lamenting perceived governmental inefficiency at both the national and subnational levels. In the United States, a pattern of divided democracy at the national level and in many states, as well as a general systemic fragmentation, has made formation of consensus on important issues difficult (Ginsberg and Shefter 1990; Fiorina 1992; Jones 1994). In Canada, prolonged haggling over core constitutional issues has obscured serious exploration of important domestic concerns (Weaver 1992). In both nations, enormous fiscal deficits nationally and in many major subnational governments impede governmental innovation that

*University of Michigan-Ann Arbor

Governance: An International Journal of Policy and Administration. Vol. 8, No. 1, January 1995 (pp. 58-77). (C) 1995 Blackwell Publishers, 238 Main Street, Cambridge, MA 02142, USA, and 108 Crowley Road, Oxford, OX4, IJF, UK. ISSN 0952-1895 
involves any considerable new expenditures. The emergence of new governments in both nations in recent years is unlikely to reverse these problems of governance.

Applied to environmental policy, this perception would lead to anticipation of serious shortcomings in continuing efforts to protect vital ecosystems such as the Great Lakes Basin. Despite the unprecedented levels of societal resources devoted to environmental protection, one might anticipate that neither American nor Canadian governments were employing these resources very successfully. Indeed, much evidence confirms this pessimism given the continuing fragmentation of many environmental regulatory efforts in the Great Lakes Basin. On the whole, federal (American and Canadian), state, and provincial policies pursue regulatory strategies that address each environmental medium (air, land, and water) separately. Growing evidence from the physical sciences indicates that such a regulatory approach tends to shift pollutants from medium to medium rather than reducing or eliminating them. When combined with the penchant for pollutant movement across boundaries of political jurisdictions, environmental policy becomes a perverse shell game that "transfers and transports" pollutants back and forth across medium and jurisdictional boundaries (Irwin 1989). Many of the most pressing environmental and public health problems facing the Basin stem from these cross-media shifts (Colborn et al. 1990), and it is not at all certain that new strategies will overcome these fragmenting tendencies and assure more integrated environmental policies. Furthermore, the enduring focus on responding to environmental problems after they occur (pollution control) continues to overshadow any emerging emphasis on taking anticipatory action to reduce or eliminate problems before they occur (pollution prevention).

The Basin appears particularly vulnerable to the effects of cross-media pollution. It is downwind of many major sources of air toxics, has extensive industrial, agricultural, and recreational activity that takes place along lakeshores, provides a broad expanse of water on which airborne pollutants may descend, and has a long "residence time" for water before it circulates out of the Basin. As a result, the multi-billion dollar efforts to clean up the Lakes through concentration on pollution from major point sources has been, at best, an incomplete success. More than 1,000 organic compounds, as well as metals such as lead, cadmium, mercury, and arsenic, are detectable in the Great Lakes, with air deposition the only plausible source in many instances. Toxic contamination of surface water attributable to groundwater discharge, landfill leaching, pesticide run-off from farm land, and release from lake-bottom sediments further compounds the problems facing the Basin. Much of this cross-media contamination is not attributable to illegal dumping of wastes or failure to enforce various permit standards. Instead, the irony is that much of the problem may stem from disposal strategies deemed perfectly legal under single- 
medium based legislation of states, provinces, and the federal governments of both Canada and the United States.

Nonetheless, despite pervasive skepticism toward governmental institutions and clear evidence of enduring problems in environmental policy, there are signs that considerable progress is being made toward integrating environmental management in the Great Lakes Basin. If less than a revolution, it is nonetheless evident from both quantitative and qualitative data sources that cross-media pollution is increasingly recognized as a fundamental problem and that a battery of new institutional measures are being put into place in attempting to address it. Whereas research from the mid-1980s in select states in the Basin and elsewhere in North America discovered minimal familiarity with the cross-media phenomenon, much less a significant institutional capacity to respond to it (Rabe 1986), this research from the early 1990s indicates a significant, if less than comprehensive, shift in both awareness and policy. This new-found recognition and willingness to act is reflected in environmental agencies and regional bodies as well as among environmental advocacy groups and industry. These findings indicate that especially at the state and regional levels, governmental capacity to respond to problems - even complex environmental ones - may be greater than is commonly perceived. Survey respondents, including environmental officials from around the Basin - representing government agencies, legislatures, industry and advocacy groups - indicated a far greater sense that respective states and provinces have been somewhat or highly successful in developing environmental programs that recognize the problems of cross-media pollution than was hypothesized (see Figure 1).

The quantitative portion of the analysis is drawn from an in-depth written survey. This was distributed to 1,045 individuals from diverse geographic areas and environmental policy positions around the Basin. Six-hundred and thirty surveys were returned, yielding a total response rate of 60.3 percent. These findings were supplemented by a series of case studies that were based on direct interviews and a review of relevant documents. Both the quantitative and qualitative portions of the analysis probed awareness of cross-media problems, receptivity to alternative integrative strategies, perception of political and administrative impediments to integration, and prioritization of competing environmental concerns. When combined, they offer a detailed account of prevailing attitudes and policy trends. For a fuller account of the methodologies and key findings, see Rabe and Zimmerman (1993).

From these findings one can begin to discern the emergence of a more integrative approach to environmental management in the Great Lakes Basin. An unexpectedly large and diverse number of innovations have begun to give shape to the concepts of ecosystem management and cross-media integration. These innovations have been fostered by environmental policy professionals within the Basin (Peterson, Rabe and Wong 1986; Stoker 1991). Such professionals, employed by subnational 
FIGURE 1

Success With Which Different States/Provinces Have Developed Environmental Programs That Recognize the Problems of Cross-Media Pollution

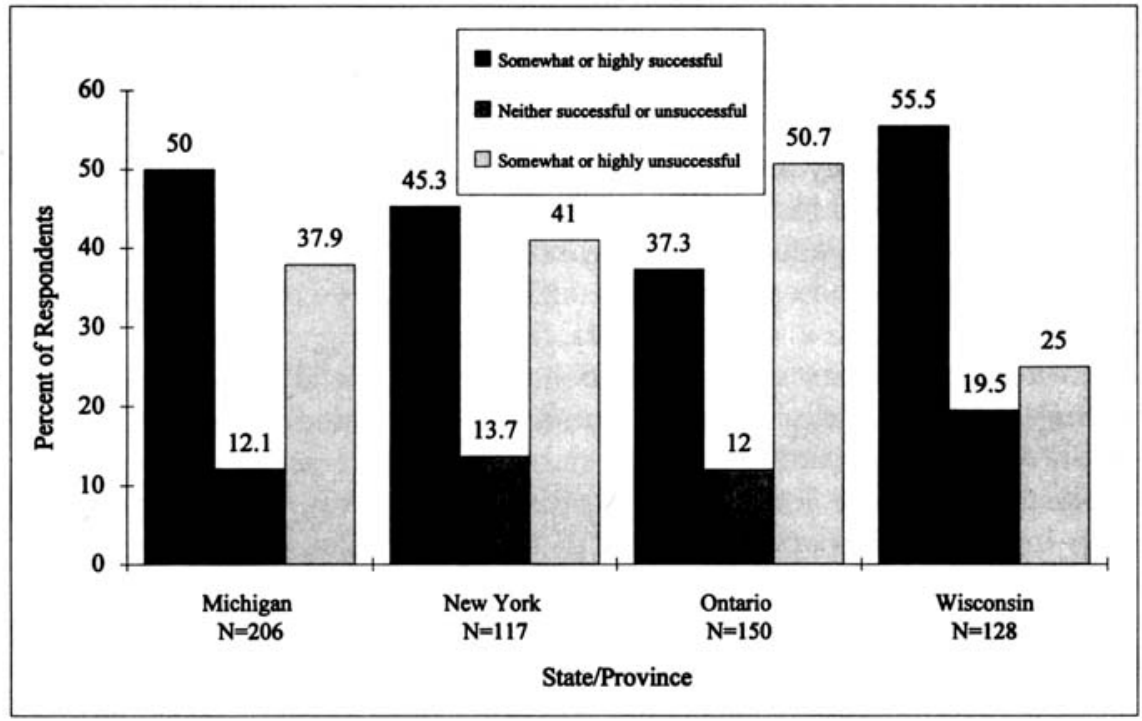

regulatory agencies, regional entities, environmental advocacy groups and industry, have demonstrated increasing creativity and willingness to challenge prevailing approaches to environmental management. They constitute the beginnings of a broader community or network, which through continued expansion and maturation could bring the promise of ecosystem management closer to realization in the Basin in the 1990s and beyond.

These environmental policy professionals must, to a large extent, continue to adhere to traditional, fragmented approaches to environmental management that have been mandated by national and subnational legislatures. Nonetheless, there is an unexpected willingness among many such individuals to not only consider alternative, more integrative approaches, but actually to take the risks inherent in developing them and attempting to implement them. Hence, one can find deputy and assistant administrators of state agencies not only overseeing implementation of single-medium, command-and-control programs but also experimenting with various kinds of organizational mechanisms to minimize the likelihood of cross-media or cross-border pollutant transfer. Similarly, one can find officials of regional environmental bodies who often must protect their core, sometimes narrow, mission and constituencies, and yet prove increasingly willing to explore partnerships with other bodies and encourage integration across individual agencies, states, and provinces. In 
addition, one can find in industry and environmental advocacy groups a growing sophistication in recognizing the inter-relatedness of varying environmental policies and the need to shift in more integrative, preventive directions.

This does not mean, of course, that major impediments to further integration will soon disappear or that these initial signs of burgeoning community for ecosystem management will soon transform all aspects of environmental policy in the Basin. But it does indicate that this sphere of domestic policy has matured rapidly in little more than two decades, and that ecosystem management and cross-media integration need no longer be dismissed as ethereal concepts unlikely to receive serious policy consideration. This view also suggests that prevailing scholarly views of environmental policy - and the behavior of regulating and regulated parties more generally - is far too narrow and cynical. Indeed, as such views increasingly influence the interpretations of scholars and policy analysts, they may lead us to dismiss prematurely the prospects for inter-institutional cooperation and policy innovation. Under such paradigms, regulating parties such as agencies are viewed as preoccupied with protecting their turf and expanding their base of resources and powers. They will meet any threat to their traditional management approaches with great resistance and will attempt to undermine rather than cooperate with rival agencies or other key entities. In the parlance of environmental management, once medium and jurisdictional boundaries have been firmly established, they will be defended vigorously by those who stand to benefit from their maintenance. In fact, many theorists would expect other key constituencies, including environmental advocacy groups and industry, to also become increasingly rewarded by and enmeshed in this established approach (Wilson 1989; Niskanen 1971; Arnold 1979; Blais and Dion 1991; Guruswamy 1989; Krier and Brownstein 1991; Wood 1988).

Such an interpretation may effectively explain much of the evolution toward single-medium environmental management in Canada and the United States in the 1970s and 1980s. It may further explain much of what persists at the federal level in both nations and in many enclaves of environmental policy within individual states and provinces. However, a shift appears to be occurring in the Great Lakes Basin, one that features the sorts of innovations and systemic changes that suggest far greater receptivity to new ideas and approaches than more cynical theorists would anticipate. In particular, there are some unexpectedly strong signs of intra- and inter-institutional partnerships that pursue the broader common good rather than the narrow self-interest (March and Olsen 1989; Mansbridge 1990). A central component in this shift is a new breed of environmental policy professional, one perhaps not yet dominant in environmental policy but increasingly influential in the formation and implementation of policy, at least within the Great Lakes Basin. Rather than narrowly protecting existing turf, such a policy professional is increas- 
ingly conversant with the concepts of integrated environmental management and is prepared to put considerable effort into the task of trying to operationalize such concepts.

These developments not only offer a more sanguine view of environmental policy but also represent a basic change in the debate over the future of environmental management. Rather than arguing over whether integrated environmental management could ever be moved from concept to practice, a dominant theme in the mid-1980s, we now have a significant body of innovations that can be examined and expanded if desired. We also have a growing community of policy professionals eager to experiment further with and develop integrated environmental programs. This shifts the debate from its highly-theoretical origins to one increasingly grounded in real practice and experience. Any discussion of the future of integrated environmental management in the Great Lakes Basin must begin with a review of enduring impediments. This analysis will be followed by a more detailed review of the factors that appear to be contributing toward greater integration in recent years.

\section{ENDURING IMPEDIMENTS TO INTEGRATION}

The significant steps being taken toward integrated environmental management in the Great Lakes Basin, of course, remain in very early stages of development. Any emerging policy community supportive of integration must be expanded and solidified, new ideas must be refined and applied, and individual state and provincial innovations must be adopted on a broader scale before more extensive integration can conceivably take place. These changes will have to occur despite a series of significant impediments which continue to hamper cross-media integration in the Great Lakes Basin. Indeed, alongside the finding that unexpectedly large changes are underway is the recognition that any transition from singlemedium to cross-media strategies will not be easy, either intellectually or politically. The following emerge as among the primary obstacles to taking more significant steps toward integration in the balance of the 1990s and beyond.

\section{Single-Medium Focus of Federal Policies}

Perhaps the single most remarkable aspect of the shift toward integration in the Basin is the fact that it has occurred in the absence of support from central governments in Washington and Ottawa. The federal governments of both the United States and Canada do little to encourage cross-media integration and, in at least the former case, do much that actually thwarts integration at the state or regional level. In the United States, the federal government retains its well-entrenched system of medium-based, command-and-control regulatory programs that are imposed upon states and regions. A combination of federal regulatory sticks and funding carrots 
continue to give individual state or regional entities pause before considering integrative innovation (Rosenbaum 1994; Landy, Roberts and Thomas 1990; Marcus 1980). In Canada, the federal government is less of an impediment to provincial innovation due to its minimal involvement in environmental matters. Nonetheless, to the extent that Canada has devised environmental legislation, it has tended to model its efforts after those of earlier programs in the United States which were clearly medium-oriented (Hoberg 1991). In both nations, occasional attempts to devise more cross-cutting federal legislation (the 1976 Toxic Substances Control Act in the United States and the 1988 Canadian Environmental Protection Act) are widely acknowledged as having had little impact on fragmentation with federal agencies and providing few if any incentives to states or provinces to pursue integration (Davies 1991; Vanderzwaag and Duncan 1992).

Survey and interview respondents in both nations agreed that their respective federal governments should play a leadership role in fostering integrated environmental management. But they also concurred that at present their federal government was a significant impediment to such management. Many respondents noted that rhetoric from the American federal government has become increasingly supportive of cross-media integration. But they contend that this verbal support has not been accompanied by the resources or authority necessary to integrate policy at the state and regional level. Indeed, each of the last four administrators of the US Environmental Protection Agency - Lee Thomas, William Ruckelshaus, William Reilly and Carol Browner - has frequently gone on record in support of cross-media integration and integrated environmental management more generally. Reilly and Browner have made such statements with particular frequency and also championed the cause of pollution prevention within the agency. At a more concrete level of policy, however, American federal initiatives in this area appear more symbolic than substantive. The much-touted and long-delayed EPA "strategy" for the Great Lakes was finally unveiled in late 1991, but it has proven in many respects a compilation of existing strategies rather than any bold new initiative. The agency has elevated the profile of its Great Lakes National Program Office, but neither it nor Congress has chosen to delegate much authority to this organization. The Clinton Administration has clearly given greater attention to environmental matters than its two predecessors but its commitment to integration or regionalism remains unclear. No major efforts to advance either of these goals have been undertaken during its first two years in office, although Administrator Browner unveiled a plan in July 1994 that promises study of integration options within specific industrial sectors.

The American difficulty in designing Basin-wide policy with an integrative focus has been compounded by the problem of securing commitments from the Canadian federal government for a comprehensive strategy. As noted earlier, the Canadian preoccupation with its constitu- 
tional crisis and the historic delegation of environmental regulatory authority to individual provinces make it a weak partner in discussion of integrative policy options for the Great Lakes Basin. If anything, Canadian environmental legislation and Environment Canada have made less progress than their American counterparts in viewing the Great Lakes Basin as a unified entity that may benefit from a coordinated regulatory approach. If not a formal impediment to provincial integration, the Canadian federal government has proven unable or unwilling to prod or entice border-sharing provinces Ontario and Quebec to work cooperatively on environmental concerns, much less work with neighboring states (Kennett 1990; Skogstad and Kopas 1992). Moreover, the relatively closed nature of the Canadian environmental policy system provides far less opportunity than does the United States for advocacy groups to advance proposals for regulatory change, including those involving environmental management (Pross 1986; Filyk and Cote 1992). As a result, the brunt of responsibility within Canada for developing integrative, Basin-wide approaches has fallen heavily on individual provinces, primarily Ontario.

\section{Limits to State and Provincial Innovation}

The Ontario experience illustrates the inherent limitations of relying so heavily on individual states or provinces to develop an integrated system of environmental management for the Great Lakes Basin. Whereas select subnational units have made considerable strides toward integration of their respective medium-based programs, others, such as Ontario, tend to brake overall progress within the region. Both quantitative and qualitative study findings indicate that practices in Ontario fail to approach the levels of integration being attained in states such as Illinois, Michigan, Minnesota, New York, and Wisconsin (see Figure 1, for example). Ontario retains a traditional, single-medium orientation and seems likely to continue to resist integrative overtures being made by elected and appointed provincial officials. Indeed, Ontario officials and observers remain far less able than their state-level counterparts to provide concrete examples of integrative policies that have been formulated and implemented, and the translation of the integrationist rhetoric of the New Democratic Party government elected in 1989 has been largely thwarted by a series of political and economic crises. Greater attention to the concepts of sustainable development and pollution prevention is evident since the arrival of this government, but these have generally not been translated into significant policy steps. The relative paucity of staff turnover within Environment Ontario and the agency's firm resistance to the preferences of political appointees have made it far more difficult to introduce and implement new regulatory approaches than in many neighboring states. In the absence of substantial pressure on Ontario, from either federal or binational authorities, to integrate environmental management, any Ba- 
sin-wide strategies face a serious stumbling block from this pivotal Canadian partner.

The potential impact of subnational innovation on integrated environmental management in the Basin is further mitigated by the uneven performance of particular states. Individual states - and policy entrepreneurs supportive of cross-media integration - have few formal mechanisms for acquiring information concerning innovation beyond their boundaries. This complicates the process of cross-fertilization of various reform initiatives that might accelerate the process of integration on a larger scale and facilitate greater multi-state coordination.

In addition, it remains unclear whether new steps toward integration with select states will continue in the face of serious fiscal problems. A number of the most promising innovations remain somewhat peripheral to the traditional core missions of state environmental agencies (implementation of medium-based and federally-funded pollution control programs) and could indeed be vulnerable to near-term budgetary shortfalls. It is also conceivable that, in such a climate, the concept of integration could be elevated to legitimize wholesale dismantling of a state's environmental management system. An example of this may be provided by recent developments in Michigan where Governor John Engler has long condemned perceived inefficiencies in the state's management of environmental programs and suggested that this has curbed economic growth in his state. His recent efforts to eliminate many staff positions and more than a dozen environmental commissions have been advanced, in part, on the argument that greater coordination is needed. However, many observers note that these actions appear to have been taken without consideration of how policy decisions might actually be integrated under this streamlined regime. They fear that these changes, upheld in a 1993 state court decision, may serve primarily to make regulatory compliance substantially easier for affected industries. In any event, the Michigan example indicates how vulnerable recent state efforts to foster more integrated environmental management may be to shifting political currents.

\section{Weak Regional Institutions}

The number of entities with some responsibility for environmental management on a Basin-wide scale has expanded in number and scope in recent years. A number of these demonstrate considerable promise for introducing greater awareness of cross-media pollution and various mechanisms for integrating policy on a region-wide basis. Nonetheless, each of these entities tends to possess fairly limited capacity to compel individual states, provinces, or industries to act in an integrated fashion. Some of the most influential and promising of these bodies, such as the Council of Great Lakes Governors and the Great Lakes Commission, lack any formal representation or involvement from Ontario or the Canadian 
federal government. Similarly, regional efforts to develop uniform water quality standards, through the Great Lakes Water Quality Initiative, proceed without comparable Canadian federal or provincial government commitments. Thus, the concept of regional environmental governance that operates in the best interest of the Great Lakes ecosystem remains, at best, a poorly defined one.

Both the maturation and continued limitation of environmental regionalism were perhaps most prominently on display at the 1991 and 1993 Biennial Meetings of the International Joint Commission. A diverse array of organizations and individuals gathered to debate pressing environmental issues. Many of these discussions emphasized the problems of cross-media pollutant transfer and endorsed the need for devising more integrative strategies, such as pollution prevention. But the atmosphere resembled what some called a "political carnival" more than a serious forum for taking concrete steps toward integrated environmental management. The commission has long played a visible role in Great Lakes water quality matters and has become an important vehicle for elevating consciousness on issues such as cross-media transfer and transport, but it has limited institutional capacity to translate broad visions into integrated policy. The development of regional institutions with greater capacity to foster integrated environmental management remains a major challenge for future policy development.

\section{STEPS TOWARD INTEGRATED ENVIRONMENTAL MANAGEMENT}

The emergence in recent years of policy professionals and institutional measures dedicated to the development of integrated environmental management in the Great Lakes Basin is remarkable given such substantial impediments. This evolution suggests a political process at odds with more conventional interpretations of political and regulatory behavior. Indeed, the development of this community of professionals, though remaining in early stages, indicates that, at least in certain circumstances, broad interests can eclipse narrow ones and that broad coalition building is possible in environmental management.

More traditional interpretations of politics, as noted above, anticipate that highly particular interests would be reluctant to yield turf and work in a cooperative, more integrative manner. According to realist and neorealist theory in international relations, moreover, only strong central authorities are likely to succeed in imposing any semblance of multi-state coordination (Keohane 1984). Such hierarchical theories have also been applied to domestic intergovernmental affairs, particularly in federal systems of government such as the United States and Canada. Applied to environmental management in the Great Lakes, fragmentation along medium, sector and jurisdictional lines could well be expected in the absence of some strong commands from Washington, Ottawa, or binational institutions such as the International Joint Commission. 
No integrating orders from central governments have been issued and none are anticipated. Nonetheless, study findings indicate considerable movement toward integration and the beginnings of a policy community devoted to integrated environmental management in the Basin. In many respects, this evolution follows the general, "bottom-up" pattern toward environmental coordination found by Elinor Ostrom in her analysis of the protection of "common-pool resources" (Ostrom 1990). Moreover, the politics underlying this shift resemble those found in other spheres of policy, such as economic deregulation of the late 1970s and early 1980s, tax reform of the mid-1980s, and military reorganization of the late 1980s and early 1990s (Mucciaroni 1992). In each of these American cases, a growing recognition of the shortcomings of existing, fragmented approaches to policy were accompanied by conceptual development of reform proposals. Despite strong resistance from narrow interests which preferred the fragmented status quo, whether protected industries, tax payers, or military branches, the broader interest was ultimately triumphant in policy reform. A somewhat similar pattern is also evident in the evolution of the Canadian system of national health insurance in the 1950s and 1960s (Taylor 1990).

The shift toward integrated environmental management in the Great Lakes Basin appears far more gradual than these other reforms, but does illustrate the growing appeal and coherence of an approach that favors the broad interests of the ecosystem over narrow preferences of regulating and regulated parties. It reflects a trend in regional policymaking that was considerably more difficult to detect as recently as a half-decade ago. Consistent with our findings, one of the leading analysts of Great Lakes environmental policy has recently written that the "principles of ecosystem management are very slowly, but steadily filtering into the programs, practices, philosophies and even legislative authorities of management agencies at the state, provincial, federal and regional levels" (Donahue 1992).

One environmental analogue to the sort of political evolution we perceive in the Great Lakes Basin is the case of environmental management in the Mediterranean Sea over the past decade. Regulatory coordination of any sort would seem particularly difficult in this area, since more than 30 nation-states with very different economies and systems of environmental management have historically caused profound environmental contamination. Obvious problems of organizing collective action existed as individual nations faced few incentives to reduce on a unilateral basis pollution releases into the water from various media and no overarching institutions existed to command or compel coordinated burden sharing.

However, as scholars such as Peter Haas have noted, substantial international cooperation has emerged in recent years in attempting to clean up the Mediterranean Sea through the so-called Mediterranean Plan. In Haas' view, the idea of broad benefit from widespread collective action has become increasingly appealing and an "epistemic community" of 
policymakers, science experts, and active citizens has emerged in the Mediterranean to build support for a broad, ecosystem-type approach that requires multilateral commitment (Haas 1990; Young and Orshenko 1993). Such a community, according to Haas, consists of environmental policy professionals from both inside and outside of government who share common beliefs about cause-and-effect relationships, as well as similar value orientations, leading them to draw similar conclusions about appropriate policy responses to the problems that concern them. Haas emphasizes that traditional approaches to international relations, and political behavior more generally, largely overlook the possibility of such political developments. But, at least in this particular case, such broad coordination has been possible, as "Mediterranean governments have gradually adopted more comprehensive policies in a coordinated fashion in order to control pollution from a growing range of sources, pollutants, and channels" (Haas 1990). In turn, Ostrom offers somewhat comparable examples of coordination in the management of "commonpool resources," although these generally do not approach the physical expanse or jurisdictional diversity of the Mediterranean Sea (Ostrom 1990).

Coordination in the Great Lakes Basin is, in many respects, considerably more advanced than the case of the Mediterranean as presented by Haas or other prominent international cases (Young and Orshenko 1993). Recent developments in the Basin thus reflect a somewhat similar path that helps to explain why the prospects for multi-state, multi-provincial, multi-institutional, and multi-interest coordination appear far greater than a decade ago. In the Basin, a diverse policy community is increasingly exercising influence over numerous aspects of environmental management in the Basin and could expand its role in future years.

This community is to a large degree propelled by a new variety of environmental policy professionals with similar beliefs and value orientations concerning environmental management. These individuals can be located throughout the Basin, on legislative staffs and in regulatory agencies as well as in environmental advocacy groups and industry. Many have become "policy entrepreneurs" in their respective state, province, or network, elevating awareness of the cross-media problem and advancing proposals that might foster greater integration (Rabe 1986). Such individuals are clearly more numerous and influential than at any prior time in the history of environmental management in the Basin. Contrary to previous periods, more recent interviews with such professionals indicate considerable conversance with the limits of medium-specific, pollution control programs and willingness to explore more integrative alternatives.

Survey findings indicate that such policy professionals may have a much broader potential following than might be anticipated. They suggest that, at least at a fairly general level, steps toward greater integration of environmental management have considerable support. Perhaps most 
striking are the survey findings that reveal unexpectedly high levels of support for more than two dozen strategies and management functions that have been proposed to reduce fragmentation. Such strategies, for which more than $75 \%$ of respondents indicated support, include integrated permitting, mandatory cross-media analysis by agencies, waste reduction programs and expanded staff training. Moreover, respondents feel strongly that integrated environmental management should be a high priority in future years. As indicated in Table 1, a number of issues directly related to greater integration (pollution prevention/waste reduction; integrated/comprehensive management; and cross-media/multimedia pollution, among others) received unexpectedly solid support in relation to other issues that respondents thought should receive top priority in the decade ahead. This indicates a wider potential constituency for such regulatory approaches than would be anticipated from historic patterns and the tone of much of the existing literature.

It is unclear whether sentiments expressed in a survey are likely to be translated into political action (and new policy) at any future point. However, all survey respondents were assured confidentiality, so they were free to state their own viewpoints. This suggests that while formation of cohesive political communities to pursue further integration may remain difficult in practice, it may well not be an insurmountable obstacle. Moreover, the emergence of such a community and the existence of a growing number of management innovations provide the beginnings of a base for further integration. The following sections further discuss some of the factors contributing to the view that a community supportive of integrated environmental management in the Basin is beginning to emerge and may develop further in future years.

\section{New Ideas and the Emergence of Pollution Prevention}

Much of the existing scholarly literature on integrated environmental management is couched in cosmic terms that seem to defy translation into coherent policy. There remains great uncertainty as to what is meant by terms such as "ecosystems" and "holistic decision making," much less firmly established strategies for integration (Bartlett 1990). Even longstanding programs such as environmental impact assessment tend to lack clear definition and rules for application.

The findings suggest, however, that there is an increasingly clear grasp of the dynamics of cross-media pollution and a growing capacity to craft initiatives designed to better integrate environmental management. This ranges from new analytic techniques such as development of mass balance analysis that systematically measures pollutant outputs of a given system to organizational tools such as integrated permitting, integrated monitoring and enforcement, agency reorganization, and environmental impact assessment. These tools are being used with increasing frequency and fairly broad political support around the Basin. All of these innova- 
TABLE 1

Issues Related to the Environment or to Environmental Management That Should Receive Top Priority in the Coming Decade*

\begin{tabular}{|c|c|c|c|c|}
\hline Issue & $\begin{array}{c}\text { Top } \\
\text { Priority }\end{array}$ & $\begin{array}{l}\text { Second } \\
\text { Priority }\end{array}$ & $\begin{array}{l}\text { Third } \\
\text { Priority }\end{array}$ & $\begin{array}{l}\text { First, Second or } \\
\text { Third Priority }\end{array}$ \\
\hline $\begin{array}{l}\text { Hazardous/solid waste } \\
\text { management (includes } \\
\text { incineration) }\end{array}$ & 86 & 93 & 53 & 232 \\
\hline $\begin{array}{l}\text { Pollution prevention/ } \\
\text { waste reduction }\end{array}$ & 108 & 68 & 42 & 218 \\
\hline $\begin{array}{l}\text { Water quality/pollution/ } \\
\text { toxics (includes surface, } \\
\text { groundwater, and drinking } \\
\text { water; general and Great } \\
\text { Lakes) }\end{array}$ & 67 & 85 & 60 & 212 \\
\hline $\begin{array}{l}\text { Air quality/pollution/ } \\
\text { toxics }\end{array}$ & 46 & 51 & 34 & 131 \\
\hline $\begin{array}{l}\text { Integrated/comprehensive } \\
\text { environmental management/ } \\
\text { ecosystem approach; general } \\
\text { and Great Lakes (including } \\
\text { integrated permitting) }\end{array}$ & 47 & 26 & 23 & 96 \\
\hline $\begin{array}{l}\text { Cross-media/multi-media } \\
\text { pollution }\end{array}$ & 13 & 26 & 20 & 59 \\
\hline Land use management & 15 & 12 & 20 & 47 \\
\hline Greater public awareness & 9 & 19 & 19 & 47 \\
\hline Recycling & 10 & 10 & 15 & 35 \\
\hline Research and development & 10 & 10 & 15 & 34 \\
\hline $\begin{array}{l}\text { Wildlife and habitat } \\
\text { protection }\end{array}$ & 10 & 11 & 11 & 32 \\
\hline Enforcement and compliance & 3 & 20 & 8 & 31 \\
\hline $\begin{array}{l}\text { Risk assessment/ } \\
\text { analysis }\end{array}$ & 13 & 10 & 4 & 27 \\
\hline
\end{tabular}

*We asked respondents the following open-ended question: "Which three issues related to the environment or to environmental management in your state/province do you think should receive top priority in the coming decade? Please identify them below." Five-hundred and eighty respondents answered. Issues mentioned less than 20 times as one of the top three priorities are not listed.

tions give coherence to discussions of integrated environmental management. They also make possible a body of ongoing experiments that will allow a testing of their potential impact in upcoming years.

Perhaps the most important single development in integrated environmental management is the emergence of pollution prevention as a unifying rallying cry for reform. Preventive environmental strategies have never received more than one percent of the resources devoted to environmental protection in nations such as the United States, but they have received unprecedented attention in recent years throughout the Great 
Lakes Basin, and other parts of the United States and Canada (John 1994). Much of the attraction behind preventive strategies stems from the growing evidence of the limitations of pollution control efforts, including the pervasive phenomenon of cross-media shifting of pollutants. Moreover, as the evidence of adverse health effects stemming from toxics contamination of the Basin continues to expand, the case for preventive, integrative strategies are likely to become all the more compelling (Colborn et al. 1990).

It remains much too soon to discern whether the idea of pollution prevention will serve to transform environmental policy in the Great Lakes Basin. But it offers, in the words of one environmental policy analyst, a "potential common metric" for examining integrated management options and moving away from a medium-based system concentrated on pollution control and reaction to environmental disasters. It also gives signs of holding great appeal to diverse constituencies due to its capacity for both bringing about significant improvement in environmental quality and doing so in a highly-efficient manner (Hirschhorn and Oldenburg 1991; Haigh and Irwin 1990).

\section{State and Provincial Innovation}

In prior decades, it would have been highly unlikely for large numbers of individual state governments to take the lead in devising integrated environmental management strategies. In the 1960s and 1970s, most states had limited environmental policy expertise, much less capacity to develop comprehensive programs. Even into the 1980s, states accepted many environmental policy marching orders from Washington, remaining eager to secure federal funding to implement single-medium pollution control programs. Provinces similarly were unlikely sources of integration in this period.

By the mid 1990s, however, there is at least some evidence of experimentation with more integrative approaches by every state and province in the Great Lakes Basin. This is consistent with a general pattern of state innovation in environmental policy during the 1980s as both environmental expenditures and regulatory capacity increased markedly in many states in the region (Lester 1994; John 1994; Ringquist 1993). The growing willingness of individual states to devise innovative approaches to environmental and other social problems in the past decade is reflected in a number of very promising efforts. Several of these could serve as models worthy of emulation by neighboring states or provinces on a region-wide basis.

Consistent with more general analyses of varying state commitment to environmental protection, certain states appear with frequency in these discussions, particularly Minnesota, New York, and Wisconsin. In Minnesota, pollution prevention has moved to center stage of state environmental policy deliberations and a series of new programs has been put 
into place during the past four years. Much of the impetus behind pollution prevention in the state stems from a series of state-sponsored hearings on the problems of cross-media pollution and barriers to integrated environmental management. A further impetus has been the collapse of the state's long-term effort to site a major, publicly-subsidized hazardous waste disposal facility and its eagerness to shift emphasis from waste disposal to waste reduction and minimization (Rabe 1994). Its innovations include mandatory pollution prevention planning by major industries, integrated inspection of facilities along Lake Superior, and a "flexible permit" program that integrates permit requirements and increases compliance flexibility in exchange for substantial emission reductions. In New York, a long-standing use of environmental impact assessment in integrative ways has been supplemented in recent years by a number of new initiatives involving permit integration and pollution prevention. In this state, a base of policy professionals supportive of integration has long been evident and has only expanded and solidified in recent years, particularly within the New York Department of Environmental Conservation. In Wisconsin, state officials have undertaken a variety of administrative reforms designed to foster better integration of environmental management. These innovations have included creation of technology teams from multiple disciplines and medium programs in addressing specific issues, rotation of staff across traditional program boundaries, development of decentralized district offices which give multi-program coordinating authority to district directors, and creation of task forces to explore permit integration options. Here, too, a number of environmental policy professionals, particularly within the state Department of Natural Resources and legislature, have provided essential support behind these innovations. Numerous examples from other states and Ontario are also evident, albeit less frequent than in these more innovative states.

\section{Resurgent Regionalism}

The growing base of support for integrated environmental management in the Basin has coincided with an increasing tendency to define and examine policy options on a region-wide basis. Constitutional and political forces continue to concentrate most environmental management authority within federal and subnational units of government. However, the last half-decade indicates tremendous growth in the tendency to define environmental management in Basin-wide terms and attempt to devise management innovations best suited for that level. Perhaps more so than in any other North American ecosystem, one can begin to trace a clear set of roles for regional institutions in fostering integrated environmental management on a regional basis. New initiatives may prove especially promising in this area in the near term.

The proliferation of regional activities creates an added layer of complexity that, to some extent, further complicates the problem of integrated 
environmental management in the Basin. Indeed, a future challenge for those involved in regional policymaking is fostering greater inter-institutional coordination and providing greater direction in integrating the various pieces of the existing environmental management system. Nonetheless, a number of institutions have begun to play a significant role of this sort. The Council of Great Lakes Governors, for example, has had considerable impact in building consensus on a multi-state basis and, if expanded to include Ontario, could be an important vehicle for greater coordination in areas such as environmental management. The Great Lakes Protection Fund, in turn, has begun to provide a major source of funding to expand the base of knowledge about the Great Lakes Basin, placing particular emphasis in recent funding rounds on various aspects of integrated environmental management and pollution prevention. In addition, bodies such as the Great Lakes Commission also have considerable capacity to bring diverse constituencies together and contribute to the development of integrated environmental management on a Basinwide basis. The Commission has been the primary force, for example, behind the development, with extensive stakeholder input, of an Ecosystem Charter for the Basin, which gives a strong endorsement of integrative approaches. Various Great Lakes Water Quality Agreements have also contributed to this more unified vision. The Great Lakes Water Quality Initiative, now approaching final stages of refinement, would set rigorous, uniform water quality standards for all states in the Basin. In addition, some innovations have involved multiple jurisdictions and programs in common focus on individual lakes, such as the Lake Ontario Toxics Management Plan being implemented by New York and Ontario.

Perhaps the best examples of the potential for - and current limitations of - integrated environmental management on an ecosystem basis are Remedial Action Plans (RAPs). These efforts represent a creative response to the 43 most degraded "areas of concern" around the Basin. Clearly intergovernmental, inter-agency, and inter-media in orientation, these RAPs have largely lacked the resources of institutional support necessary to test fully the viability of such a coordinated strategy. These limitations reflect the fact that they were devised by the International Joint Commission. Nonetheless, as John Hartig and Michael Zarull note in their analysis of the early stages of RAP performance, they do constitute an important first effort to operationalize integrated environmental management on a Basin-wide basis and have registered some important achievements in select cases (Hartig and Zarull 1992).

\section{CONCLUSION}

Integrated environmental management remains, in many respects, an elusive goal. Its realization continues to be blocked by federal, state, provincial, and regional impediments. Nonetheless, regulatory system changes in the Great Lakes Basin represent a growing intellectual and 
political capacity to give institutional shape to integrated environmental management in this region. The emergence in recent years of a community of environmental policy professionals with a capability to devise and implement integrative strategies indicates that regulatory fragmentation need not be an inevitability. In fact, one can see signs of greater regulatory integration both within individual subnational units and across units around the Basin. These changes have given unprecedented definition to the traditionally ethereal debates over the prospects of regulatory integration and could serve as a base for further innovation in the Basin and in other regions of North America.

\section{Acknowledgement}

Financial support from the Joyce Foundation was essential to the completion of this research and is greatly appreciated. We would also like to thank Michael Atkinson, Michael Donahue, Frances Irwin, Anne Khademian, Karl Kronebusch, and three anonymous reviewers for their helpful comments on earlier drafts, and to Debi Hegerfeld and Mary Wigton for word processing assistance. The Matthaei Botanical Gardens of the University of Michigan and the La Follette Institute of Public Affairs of the University of Wisconsin-Madison provided institutional support, for which we are also most grateful.

\section{References}

Arnold, R. Douglas. 1979. Congress and the Bureaucracy. New Haven: Yale University Press.

Bartlett, Robert V. 1990. Comprehensive Environmental Decision-Making: Can It Work? In Environmental Policy in the 1990s, eds. Norman J. Vig and Michael E. Kraft. Washington DC: Congressional Quarterly.

Blais, Andre and Stephane Dion, eds. 1991. The Budget-Maximizing Bureaucrat: Appraisals and Evidence. Pittsburgh: University of Pittsburgh Press.

Colborn, Theodora, et al. 1990. Great Lakes, Great Legacy? Washington DC: Conservation Foundation.

Davies, J. Clarence. 1991. Some Thoughts on Implementing Integration. Environmental Law 22:139-147.

Donohue, Michael J. 1990. An Ecosystem Charter for the Great Lakes. Ann Arbor: Great Lakes Commission.

Filyk, Gregor and Ray Cote. 1992. Pressures from Inside: Advisory Groups and the Environmental Policy Community. In Canadian Environmental Policy: Ecosystems, Politics, and Process, ed. Robert Boardman. Toronto: Oxford University Press.

Fiorina, Morris P. 1992. Divided Government. New York: Macmillan.

Ginsberg, Benjamin and Martin Shefter. 1990. Politics By Other Means: The Declining Importance of Elections in America. New York: Basic Books.

Guruswamy, Lakshman. 1989. Integrating Thoughtways: Re-Opening of the Environmental Mind Wisconsin Law Review 463-537.

Haas, Peter M. 1990. Saving the Mediterranean: The Politics of International Environmental Cooperation. New York: Columbia University Press.

Haigh, Nigel and Frances Irwin, eds. 1990. Integrated Pollution Control in Europe and North America. Washington DC: Conservation Foundation.

Hartig, John H. and Michael A. Zarull, eds. 1992. Under RAPs: Toward Grassroots 
Ecological Democracy in the Great Lakes Basin. Ann Arbor: University of Michigan Press.

Hirschhorn, Joel S. and Kirsten V. Oldenburg. 1991. Prosperity Without Pollution: The Prevention Strategy for Industry and Consumers. New York: Von Nostrand Reinhold.

Hoberg, George. 1991. Sleeping with an Elephant: The American Influence on Canadian Environmental Protection. Journal of Public Policy 10:107-132.

Irwin, Frances H. 1989. Integrated Pollution Control. International Environmental Affairs 1: 255-274.

John, DeWitt. 1994. Civic Environmentalism: Alternatives to Regulation in States and Communities. Washington DC: Congressional Quarterly.

Johnston, Richard. 1986. Public Opinion and Public Policy in Canada: Questions of Confidence. Toronto: University of Toronto.

Jones, Charles O. 1994. The Presidency in a Separated System. Washington DC: Brookings Institution.

Kennett, Steven A. 1990. Federalism and Sustainable Development. Alternatives 17:32-39.

Keohane, Robert. 1984. After Hegemony: Cooperation and Discord in the World Political Economy. Princeton: Princeton University Press.

Krier, James E. and Mark Brownstein. 1991. On Integrated Pollution Control. Environmental Law 22:119-138.

Lester, James P. 1994. A New Federalism? Environmental Policy in the States. In Environmental Policy in the 1990s, 2nd ed; eds. Norman J. Vig and Michael E. Kraft. Washington DC: Congressional Quarterly.

Lipset, Seymour Martin and William Schneider. 1983. The Confidence Game. New York: Free Press.

Mansbridge, Jane J., ed. 1990. Beyond Self-Interest. Chicago: University of Chicago Press

March, James G. and Johan P. Olsen. 1989. Rediscovering Institutions: The Organizational Basis of Politics. New York: Free Press.

Marcus, Alfred. 1980. Promise and Performance: Choosing and Implementing Environmental Policy. Westport CT: Greenwood.

Mucciaroni, Gary. 1992. Unclogging the Arteries: The Defeat of Client Politics and the Logic of Collective Action. Policy Studies Journal 19:474-494.

Niskanen, William. 1971. Bureaucracy and Representative Government. Chicago: Aldine-Atherton.

Ostrom, Elinor. 1990. Governing the Commons: The Evolution of Institutions for Collective Action. New York: Cambridge University Press.

Page, Benjamin I. and Robert Y. Shapiro. 1992. The Rational Public. Chicago: University of Chicago Press.

Peterson, Paul E., Barry G. Rabe, and Kenneth K. Wong. 1986. When Federalism Works. Washington DC: Brookings Institution.

Pross, A. Paul. 1986. Group Politics and Public Policy. Toronto: Oxford University Press.

Rabe, Barry G. 1986. Fragmentation and Integration in State Environmental Management. Washington DC: Conservation Foundation.

- 1994. Beyond NIMBY: Hazardous Waste Siting in Canada and the United States. Washington DC: Brookings Institution.

- and Janet B. Zimmerman. 1993. Toward Environmental Regulatory Integration in the Great Lakes Basin. Ann Arbor: University of Michigan Resource for Public Health Policy.

Ringquist, Evan J. 1993. Environmental Protection at the State Level. Armonk NY: M.E. Sharpe.

Skogstad, Grace and Paul Kopas. 1992. Environmental Policy in a Federal System: 
Ottawa and the Provinces. In Canadian Environmental Policy: Ecosystems, Politics, and Process, ed. Robert Boardman. Toronto: Oxford University Press.

Stoker, Robert P. 1991. Reluctant Partners: Implementing Federal Policy. Pittsburgh: University of Pittsburgh Press.

Taylor, Malcolm. 1990. Insuring National Health Care: The Canadian Experience. Chapel Hill: University of North Carolina Press.

Vanderzwaag, David and Linda Duncan. 1992. Canada and Environmental Protection: Confident Political Faces, Uncertain Legal Hands. In Canadian Environmental Policy: Ecosystems, Politics and Process, ed. Robert Boardman. Toronto: Oxford University Press.

Weaver, R. Kent, ed. 1992. The Collapse of Canada? Washington DC: Brookings Institution.

Wilson, James Q. 1989. Bureaucracy. New York: Basic Books.

Wood, B. Dan. 1988. Principals, Bureaucrats, and Responsiveness in Clean Air Act Enforcements. American Political Science Review 82:213-234.

Young, Oran R. and Gail Osherenko. 1993. International Regime Formation: Findings, Research Priorities, and Applications. In Polar Politics: Creating International Environmental Regimes. Ithaca: Cornell University Press. 